\title{
Self-Assembled DNA-PEG Bottlebrushes Enhance Antisense Activity and Pharmacokinetics of Oligonucleotides
} Yuyan Wang, Dali Wang, Fei Jia, Andrew Miller, Xuyu Tan, Peiru Chen, Lei Zhang, Hao Lu, Yang Fang,
Xi Kang, Jiansong Cai, Mengqi Ren, and Ke Zhang*

Department of Chemistry and Chemical Biology, Northeastern University Boston

Massachusetts 02115, United States

To whom correspondence should be addressed.

E-mail: k.zhang@northeastern.edu 


\section{Materials and methods}

Phosphoramidites and supplies for DNA synthesis were purchased from Glen Research Co (Sterling, VA, USA). Azide-terminated poly(ethylene glycol) methyl ether $\left(\mathrm{M}_{\mathrm{n}}=10 \mathrm{kDa}\right.$, $\mathrm{PDI}<1.05)$ was purchased from Sigma-Aldrich Co (St. Louis, MO, USA). Human NCI-H358 cell lines were purchased from American Type Culture Collection (Rockville, MD, USA). Human PC9 cell lines were from Dr. Zhao's lab (Dana-Farber Cancer Institute). All other materials were purchased from Fisher Scientific Inc. (Waltham, MA, USA), Sigma-Aldrich Co., and VWR International LLC. (Franklin, MA, USA), and used as received unless otherwise indicated. Aqueous GPC measurements were performed on a Waters Breeze 2 GPC system equipped with Ultrahydrogel ${ }^{\mathrm{TM}} 500$ and Ultrahydrogel ${ }^{\mathrm{TM}} 250,7.8 \AA \times 300 \mathrm{~mm}$ column and a $2998 \mathrm{PDA}$ detector (Waters Co., MA, USA). Phosphate-buffered saline (PBS, pH 7.4) was used as the eluent running at a flow rate of $0.8 \mathrm{~mL} / \mathrm{min}$. Reversed-phase HPLC was performed using a Waters Breeze 2 HPLC system coupled to a Symmetry C18 $3.5 \mu \mathrm{m}, 4.6 \AA \times 75 \mathrm{~mm}$ reversed-phase column and a 2998 PDA detector. Gel electrophoresis was performed using 5\% agarose gel in $0.5 \times$ tris/borate/EDTA (TBE) buffer with a running voltage of $120 \mathrm{~V}$ at $4{ }^{\circ} \mathrm{C}$. Prior to loading the gel, $20 \mu \mathrm{L}$ samples in sodium phosphate sodium chloride solution (SPSC, $\mathrm{pH}$ 7.5) or PBS is mixed with $5 \mu \mathrm{L}$ of loading buffer (30\% glycerol in water). Gel images were acquired on an Alpha Innotech Fluorochem Q imager. All TEM samples were imaged on a JEOL JEM 1010 electron microscope utilizing an accelerating voltage of $80 \mathrm{kV}$. DLS and $\zeta$ potential data were recorded on a Malvern Zetasizer Nano-ZSP (Malvern, UK).

\section{Oligonucleotide synthesis}

Oligonucleotides were synthesized on an ABI Model 391 DNA synthesizer (Applied Biosystems, Inc., Foster City, CA) using standard solid-phase phosphoramidite methodology. DNA strands were cleaved from the CPG support using aqueous ammonium hydroxide (28-30\% $\mathrm{NH}_{3}$ basis) at room temperature for $24 \mathrm{~h}$. All DNA strands were then purified by reversed-phase HPLC. Mobile phases for HPLC purification are triethylammonium acetate (TEAA) buffer $(0.1$ $\mathrm{M}$ ) and HPLC-grade acetonitrile, with a flow rate of $1 \mathrm{~mL} / \mathrm{min}$. The gradient method starts from $100 \%$ TEAA, increasing acetonitrile to $100 \%$ in 50 mins. The dimethoxytrityl protecting groups were subsequently removed by treatment with $20 \%$ acetic acid for $1 \mathrm{~h}$, and extracted with ethyl acetate three times in an aqueous solution. Upon lyophilization, DNA was collected and stored at $-20^{\circ} \mathrm{C}$. To synthesize modified DNA strands, Cyanine $3 \mathrm{CPG}$ and Cyanine $5 \mathrm{CPG}$ were used as the solid support and DBCO-modified dT was used to install DBCO-functional group to the DNA strands.

\section{Cell culture}

NCI-H358 and PC9 cells were cultured in RPMI media supplemented with 10\% fetal bovine serum (FBS), $1 \%$ L-glutamine, and $1 \%$ antibiotics at $37^{\circ} \mathrm{C}$ in a humidified atmosphere containing $5 \% \mathrm{CO}_{2}$.

\section{Dynamic Light Scattering}

$1 \mathrm{~mL}$ of DLS sample (10 $\mu \mathrm{M}$ equiv of ASO) was dialyzed into PBS buffer, and then filtered through a $0.2 \mu \mathrm{m}$ PTFE filter. The sample solution was added into a disposable cuvette for measurement. Data was recorded under $173^{\circ}$ backscatter measurement angle. 


\section{Transmission Electron Microscopy}

$1 \mu \mathrm{M}$ of TEM samples was deposited on carbon-coated copper grids for $10 \mathrm{~min}$ before being carefully wicked away by filter paper. The grids were then stained by depositing on $10 \mu \mathrm{L}$ of $1 \%$ uranyl acetate. The stain was allowed to stay for 3 min before being wicked away.

\section{Nuclease degradation kinetics}

$1 \mu \mathrm{M}$ of Cy5-labeled DNA assemblies (with or without PEGylation) were incubated with DNase I (0.4 unit/mL, Sigma-Aldrich) in PBS buffer solution (with $2.5 \mathrm{mM} \mathrm{MgCl}_{2}$ and $0.5 \mathrm{mM} \mathrm{CaCl}_{2}$ ) for $15 \mathrm{~min}, 30 \mathrm{~min}, 1 \mathrm{~h}, 1.5 \mathrm{~h}$ and $2 \mathrm{~h}$ with gentle shaking on an Eppendorf Thermomixer $\mathrm{C}$ at $37^{\circ} \mathrm{C}$. Thereafter, the reaction mixture was immediately mixed with loading buffer and transferred into a pre-cast $5 \%$ agarose gel. Then the gel was electrophoresed in $0.5 \times$ TBE buffer at a constant voltage of $120 \mathrm{~V}$. The gel was then imaged and analyzed by an Alpha Innotech Fluorochem Q imager using band densitometry analysis.

\section{Flow cytometry}

Cells were seeded in 24-well plates at $2.0 \times 10^{5}$ cells per well in $1 \mathrm{~mL}$ complete RPMI media and cultured for $24 \mathrm{~h}$ at $37^{\circ} \mathrm{C}$ with $5 \% \mathrm{CO}_{2}$. Then, Cy3-labeled hairpin strands, PEGylated hairpin strands, non-PEGylated assemblies, and PEGylated assemblies (500 nM-10 $\mu \mathrm{M}$ equiv of antisense DNA) dissolved in serum-free RPMI culture medium were added, and cells were further incubated at $37^{\circ} \mathrm{C}$ for $4 \mathrm{~h}$ or $24 \mathrm{~h}$. Subsequently, cells were washed with PBS $3 \times$ and suspended by treatment with trypsin. Thereafter, $2 \mathrm{~mL}$ of PBS was added to each culture well, and the solutions were centrifugated for $5 \mathrm{~min}(1000 \mathrm{rpm})$. Cells were then resuspended in $0.5 \mathrm{~mL}$ of PBS for flow cytometry analysis on a BD FACS Calibur flow cytometer. Data for $1.0 \times 10^{4}$ gated events were collected.

\section{Serum stability test}

$1 \mathrm{nmol}$ of Cy5-labeled unmodified hairpins, PEGylated hairpins, non-PEGylated assembly and PEGylated assembly were each dissolved in $100 \mu \mathrm{L}$ full-serum RPMI media (10\% FBS). $10 \mathrm{uL}$ of each sample mixture was immediately taken out as the $\mathrm{t}=0 \mathrm{~h}$ and stored at $-20^{\circ} \mathrm{C}$. The remaining samples were then incubated at $37^{\circ} \mathrm{C}$, and $10 \mathrm{uL}$ of each mixture sample was taken out at different time points: $1 \mathrm{~h}, 2 \mathrm{~h}, 4 \mathrm{~h}, 10 \mathrm{~h}$ and $24 \mathrm{~h}$, and then stored at $-20^{\circ} \mathrm{C}$. Thereafter, the collected samples were analyzed by AGE (5\%) and imaged under EB and Cy5 channel, separately.

\section{Confocal microscopy}

Cells were seeded in 24-well glass bottom plates at $1.0 \times 10^{5}$ cells per well and cultured in $1 \mathrm{~mL}$ complete RPMI media for $24 \mathrm{~h}$ at $37^{\circ} \mathrm{C}$ with $5 \% \mathrm{CO}_{2}$. Then, Cy3- or Cy5-labeled hairpins, PEGylated hairpins, non-PEGylated assemblies, and PEGylated assemblies (10 $\mu$ M equiv of ASO) dissolved in serum-free RPMI media or complete RPMI culture medium were added and cells were incubated at $37^{\circ} \mathrm{C}$ for $4 \mathrm{~h}$ and $24 \mathrm{~h}$. Thereafter, cells were washed with PBS $3 \times$ and fixed with $4 \%$ paraformaldehyde for $30 \mathrm{~min}$ at room temperature. After fixation, cells were washed with PBS $3 \times$ and kept in PBS. Then cells were stained with Hoechst 33342 for 10 min. The cells were imaged on an LSM-800 confocal laser scanning microscope (Carl Zeiss Ltd., Cambridge, UK). Imaging settings were kept identical for all samples. 


\section{MTT assay}

The cytotoxicity of DNA assemblies and controls were evaluated with the MTT assay against NCIH358 and PC9 cells. Briefly, cells were seeded into 96-well plates at $1.0 \times 10^{4}$ cells per well in 200 $\mu \mathrm{L}$ complete RMPI culture medium and cultured for $24 \mathrm{~h}$. The cells were then treated with PEGylated hairpins, DNA assemblies with or without PEGylation, and lipofectamine-complexed hairpins at varying concentrations (100 nM-10 $\mu \mathrm{M}$ equiv of antisense DNA). Cells treated with vehicle (PBS) were used as a negative control, and Lipofectamine 2000 (Invitrogen Co., CA, USA)-treated cells were used as a positive control. After $48 \mathrm{~h}$ of incubation, $20 \mu \mathrm{L}$ of $5 \mathrm{mg} / \mathrm{mL}$ MTT stock solution in PBS was added to each well. The cells were incubated for another $4 \mathrm{~h}$, and the medium containing unreacted MTT was removed carefully. The resulting blue formazan crystals were dissolved in $200 \mu \mathrm{L}$ DMSO per well, and the absorbances (490 nm) were measured on a BioTek ${ }^{\circledR}$ Synergy ${ }^{\mathrm{TM}}$ Neo2 Multi-Mode microplate reader (BioTek Inc., VT, USA).

\section{Cell apoptosis}

NCI-H358 cells were treated with DNA assemblies and controls in the same fashion as those used in the Western blotting study. For the apoptosis analysis, both floating and attached cells were harvested, rinsed $3 \times$ with cold PBS, stained with Alexa Fluor 488 annexin V and PI, and analyzed by flow cytometry to identify apoptotic cells. 
Table S1. All DNA sequences used in this study. ${ }^{1-2}$

\begin{tabular}{|c|c|c|}
\hline System & Strand & Sequences* \\
\hline \multirow{3}{*}{ Short-length } & HP1 & 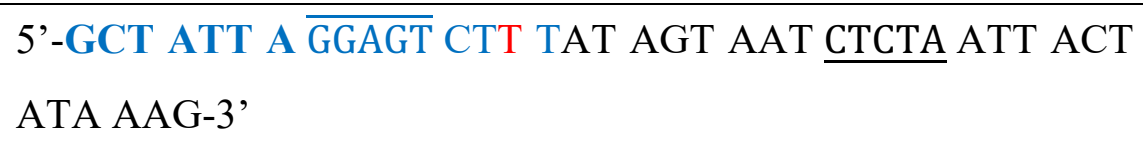 \\
\hline & HP2 & 5'-ATT ACT ATA AAG $\underline{\text { ACTCC CTT TAT AGT AAT TAGAG }}$-3' \\
\hline & Initiator & 5'-ATT ACT ATA AAG ACT CCT AAT AGC-3' \\
\hline \multirow{7}{*}{ Long-length } & HP1 & $\begin{array}{l}\text { 5'-TTAACC CAC GCC GAA TCC AAA GAC CAAAGT GTC TTT } \\
\text { GGA TTC GGC GTG-3' }\end{array}$ \\
\hline & HP2 & $\begin{array}{l}\text { 5'-GCT ATT AGG A GTC TTT GGA TTCGG CGT G GGTTAA } \\
\text { CA CGC CGA ATC CAA AGA C } \overline{\text { ACTTTG-3' }}\end{array}$ \\
\hline & Initiator & 5'-GTC TTT GGA TTC GGC GTG GGT TAA-3' \\
\hline & Сy3-HP2 & $\begin{array}{l}\text { 5'-GCT ATT AGG A GTC TTT GGA TTCGG CGT G GGTTAA } \\
\text { CA CGC CGA ATC CAA AGA C } \overline{\text { ACTTTG-Cy3-3, }}\end{array}$ \\
\hline & Cy5-HP2 & $\begin{array}{l}\text { 5'-GCT ATT AGG A GTC TTT GGA TTCGG CGT G GGTTAA } \\
\text { CA CGC CGA ATC CAA AGA C } \overline{\text { ACTTTG-Cy5-3' }}\end{array}$ \\
\hline & SCR-HP2 & $\begin{array}{l}\text { 5'-ACT GCG TTA GAG TAG GTA GAA GAT TAA CCA GTC } \\
\text { TGG TTC GCT GCA GTC TCT GCT AGA C -3' }\end{array}$ \\
\hline & $\begin{array}{l}\text { Overhang- } \\
\text { SCR-HP2 }\end{array}$ & $\begin{array}{l}\text { 5'-ATG TGA TCA G GTC TTT GGA TTCGG CGT G GGTTAA } \\
\text { CA CGC CGA ATC CAA AGA C } \overline{\text { ACTTTG }-3} \text { ' }\end{array}$ \\
\hline
\end{tabular}

*Modified T bases for PEGylation are marked in red. Hairpin loops are underlined and sticky ends are overlined. Overhangs are bolded. Antisense region is marked in blue. 
Scheme S1. Assembly of bottlebrush-like nanostructures via hybridization chain reaction.

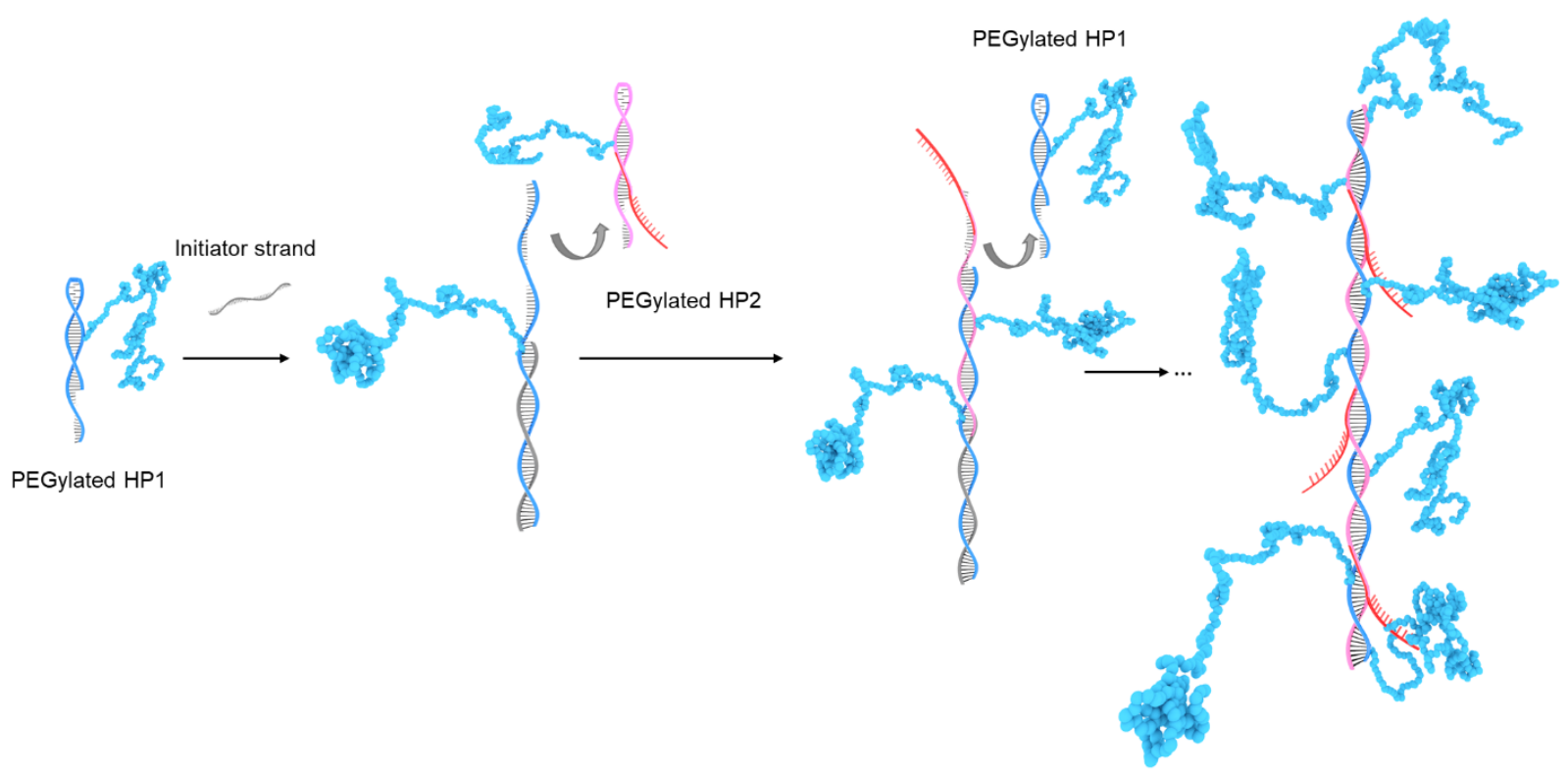

Scheme S2. Conjugation of azide-terminated PEG to DBCO-modified T base.

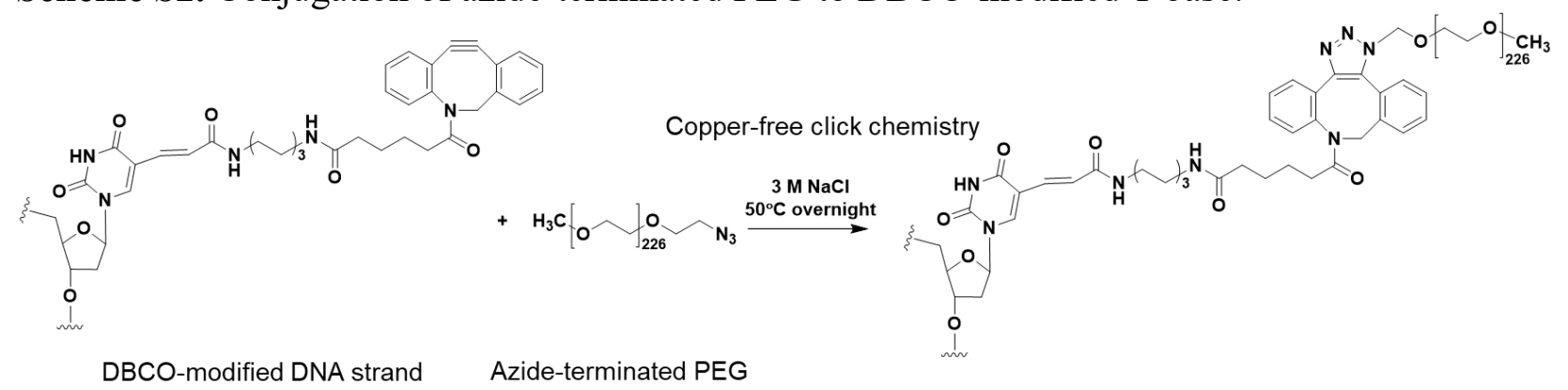



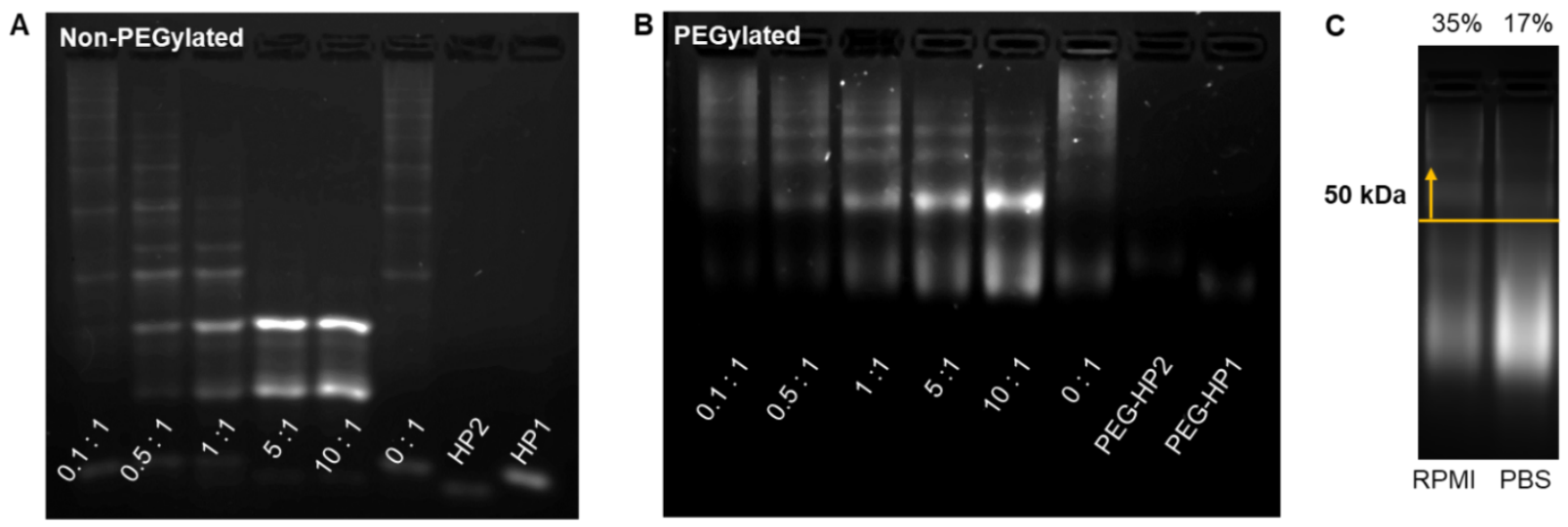

Figure S1. A, B) AGE (5\%) analysis of short-stem DNA assemblies as a function of initiator:hairpin ratio. C) AGE (5\%) analysis of short-stem PEGylated DNA assemblies after dialysis into RPMI medium or PBS.
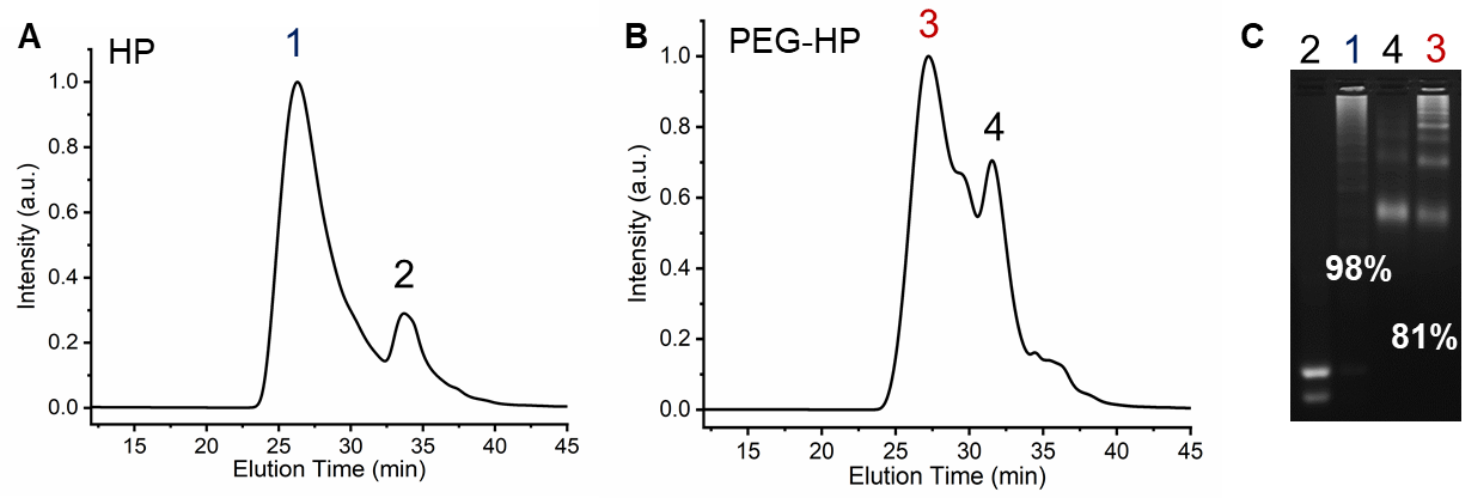

Figure S2. A, B) Aqueous GPC purification of DNA assemblies. C) AGE (5\%) analysis of high MW fraction of DNA assemblies after purification. Purity is determined by gel band densitometry analysis. 1-4: non-PEGylated assemblies, hairpin monomers, PEGylated assemblies, and PEGylated hairpin monomers, respectively. 

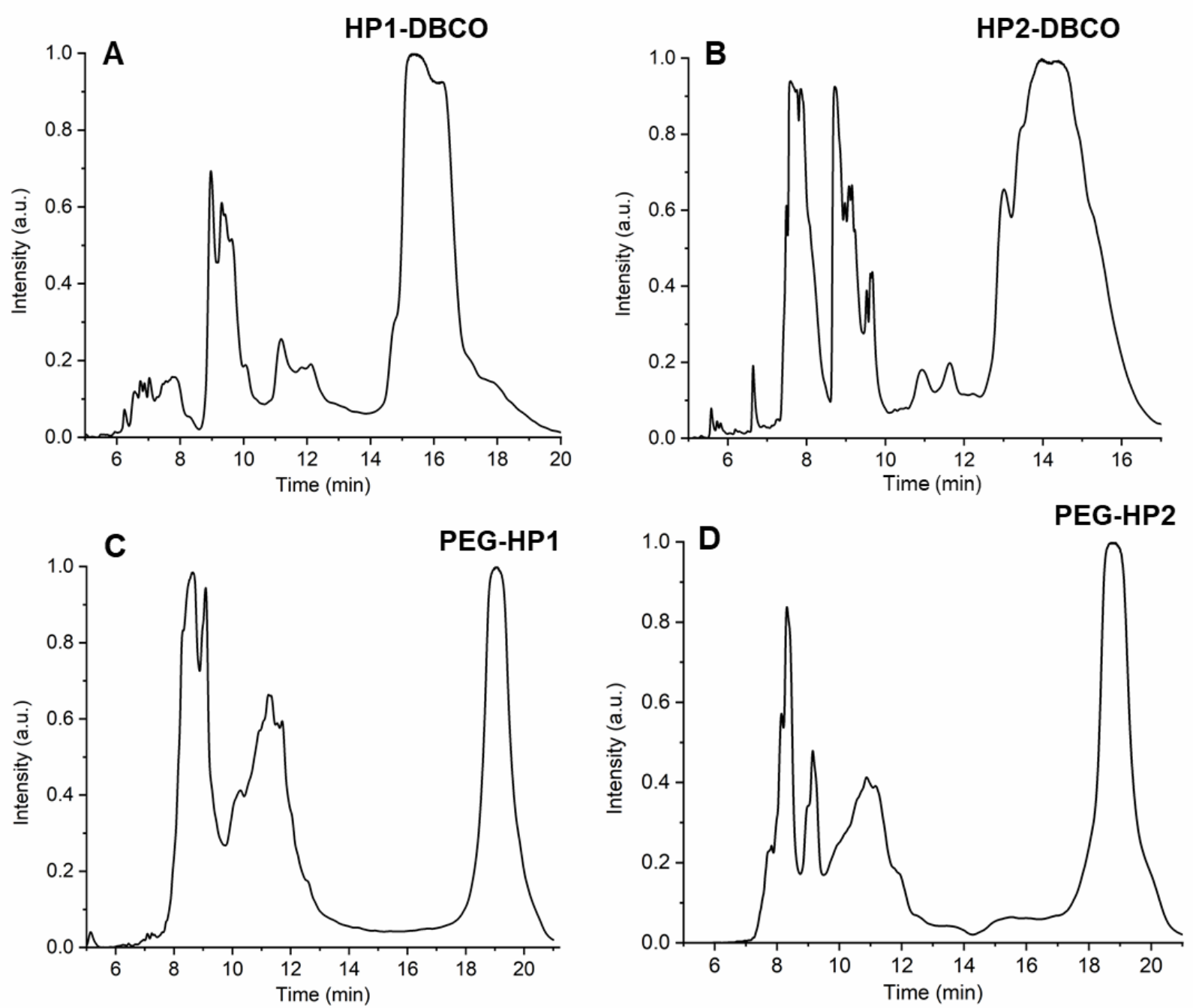

Figure S3. A, B) Reversed-phase HPLC purification of DBCO-modified hairpin strands. C, D) Reversed-phase HPLC purification of PEGylated hairpin monomers. 
A

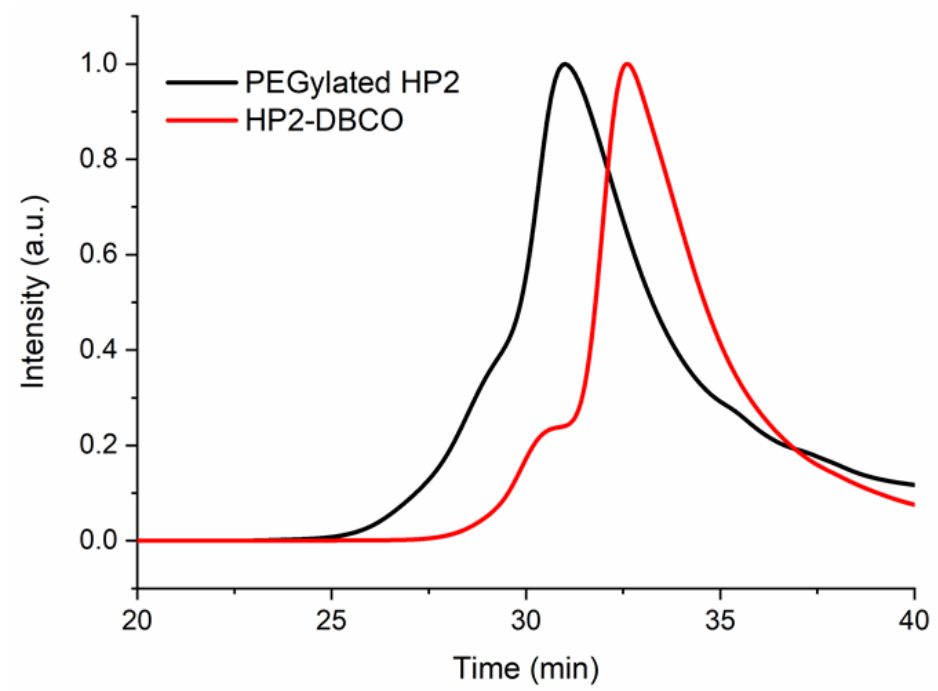

B

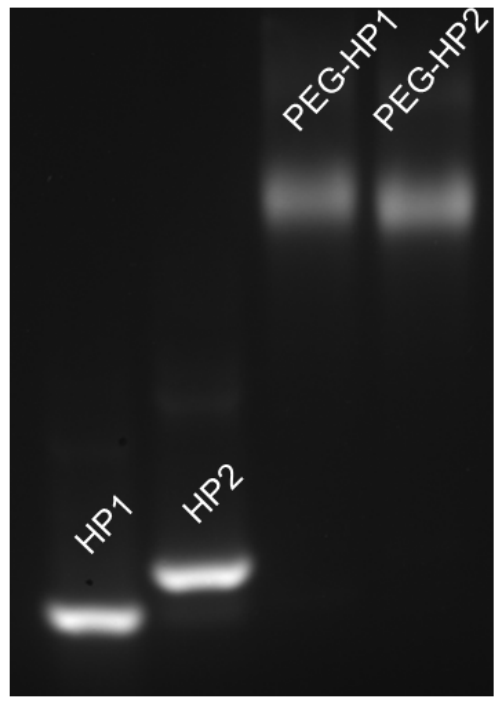

Figure S4. A) Aqueous GPC chromatogram of DBCO-modified hairpin and PEGylated hairpins. B) AGE (2\%) analysis of hairpins and PEGylated hairpins.

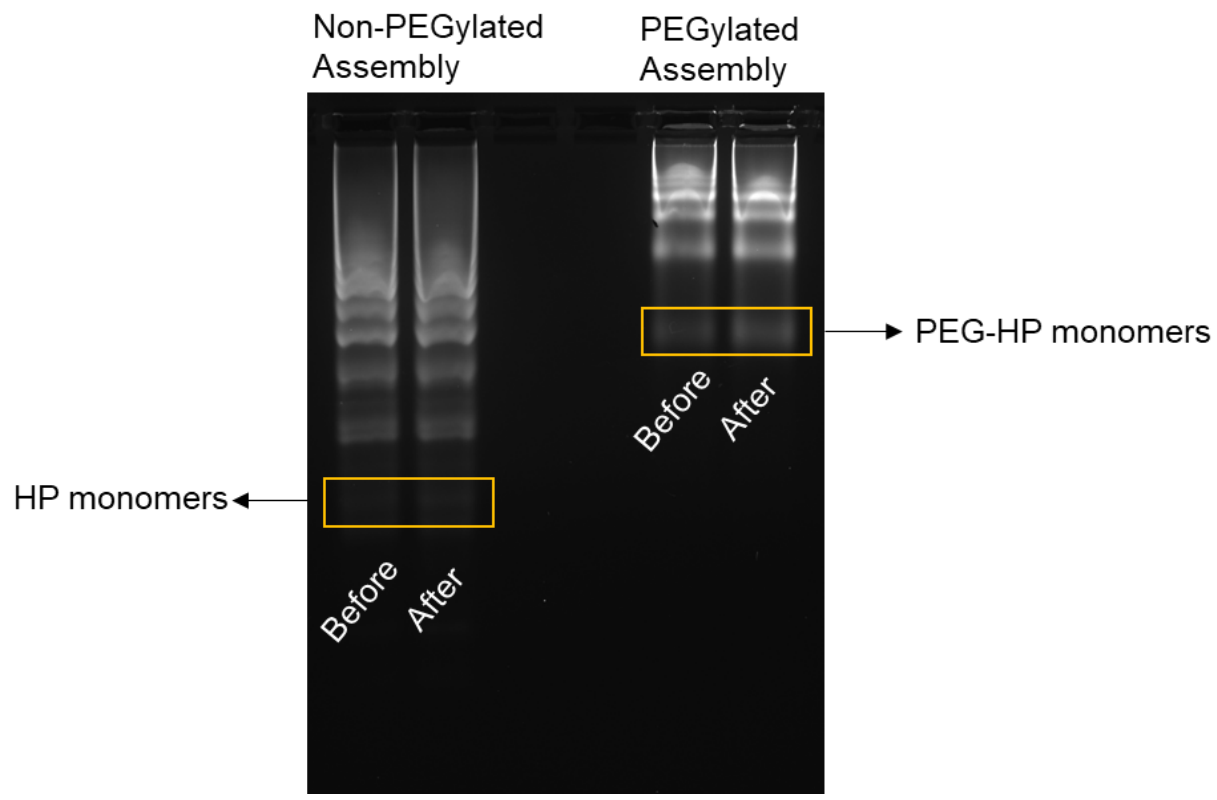

Figure S5. AGE (5\%) analysis of DNA assemblies before and after lyophilization. 


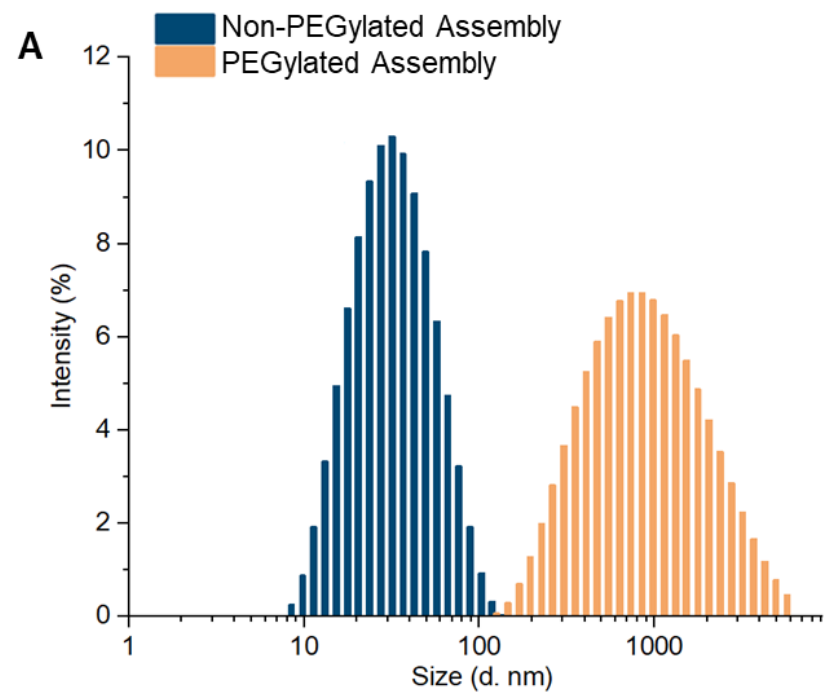

B

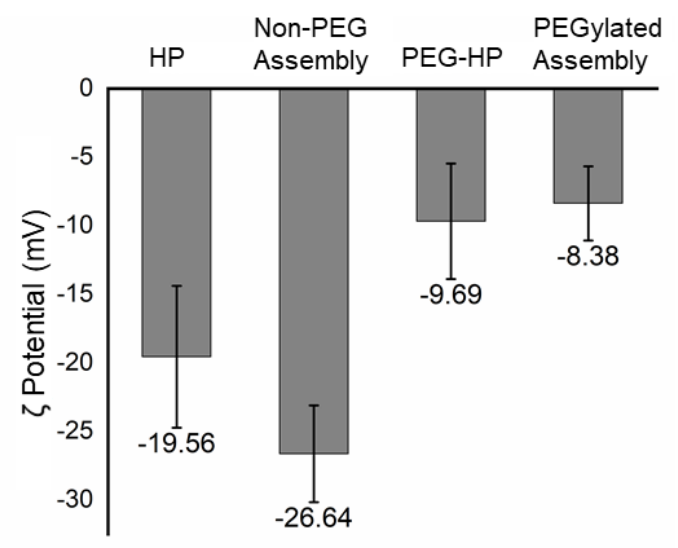

Figure S6. A) DLS intensity-average hydrodynamic diameter distribution of DNA assemblies (with or without PEGylation). (B) $\zeta$ potential measurement of DNA assemblies and their precursors in PBS.

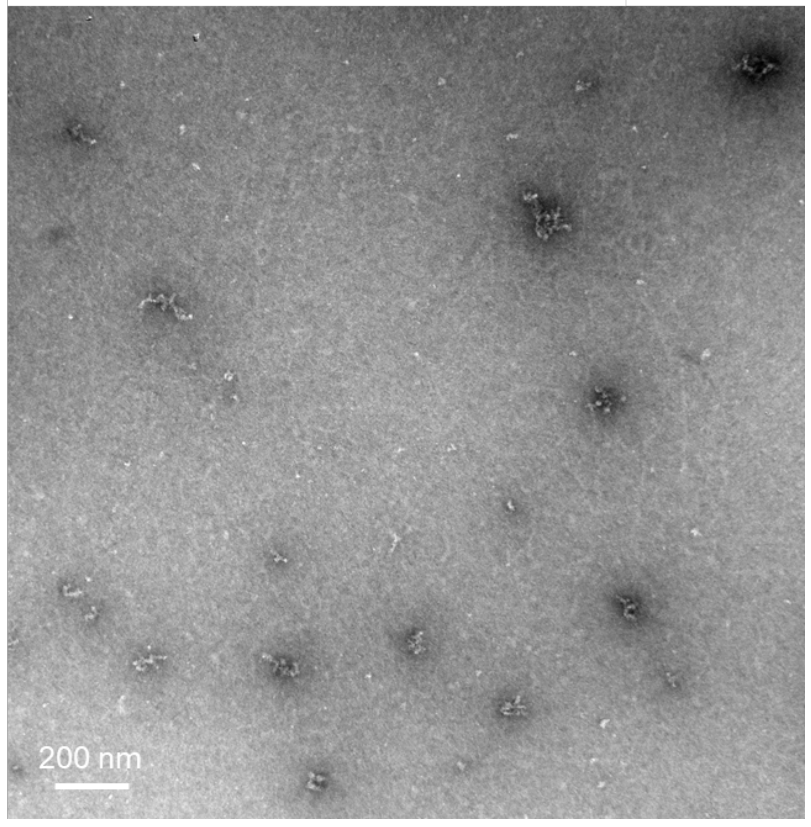

Figure S7. TEM image (negatively stained with $1 \%$ uranyl acetate) of a physical mixture of DBCO-modified HP2 and 10 kDa PEG. 

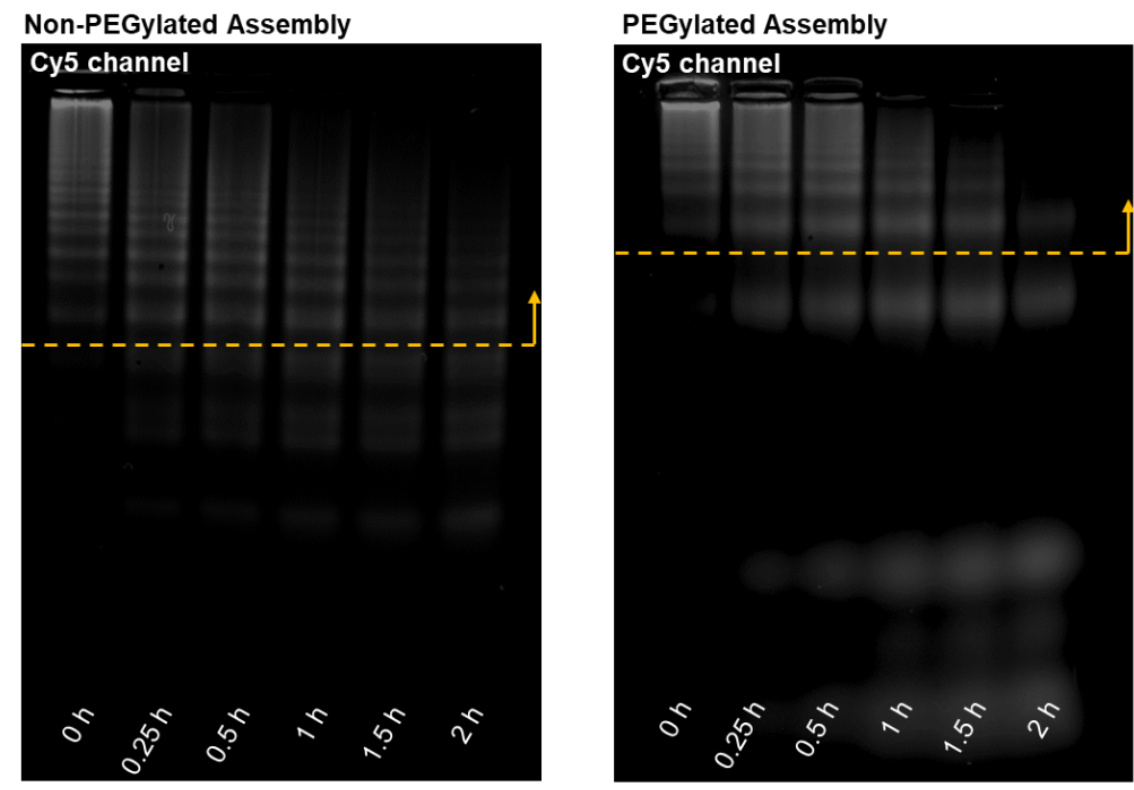

Figure S8. AGE (5\%) analysis of DNA assemblies treated with DNase I for various amounts of time (Cy5 channel). Dashed line indicates a cut-off for high molecular weight fractions $(>50 \mathrm{kDa})$.
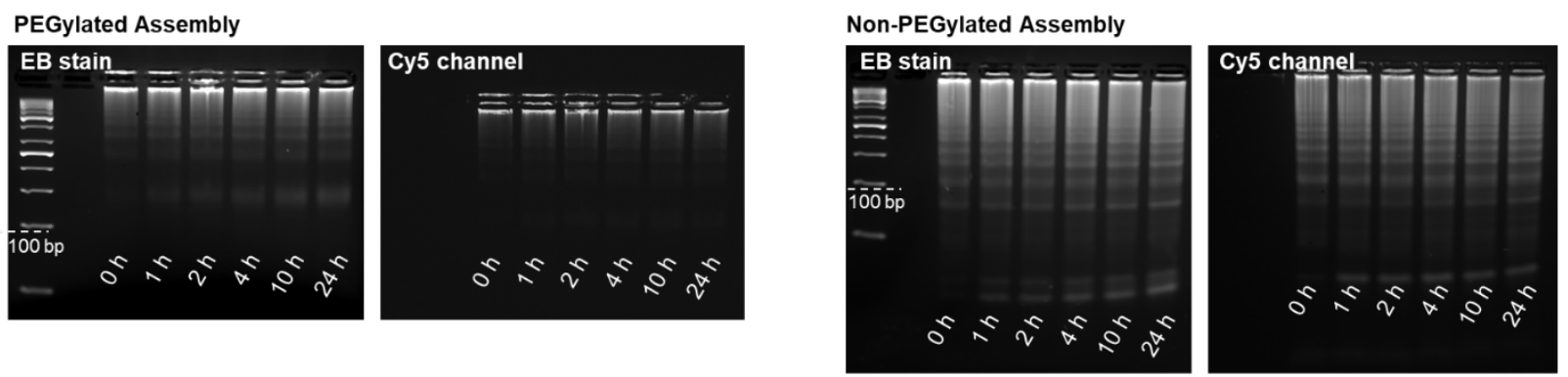

PEGylated HP2
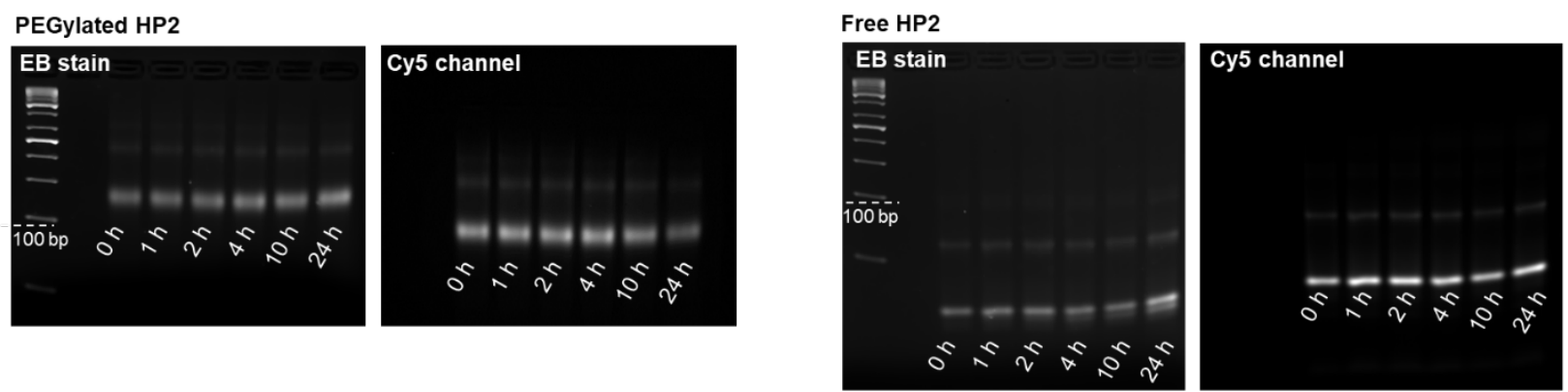

Figure S9. AGE (5\%) analysis of DNA assembly and monomers treated with full-serum RPMI medium (10\% FBS) for various amounts of time up to $24 \mathrm{~h}$. 

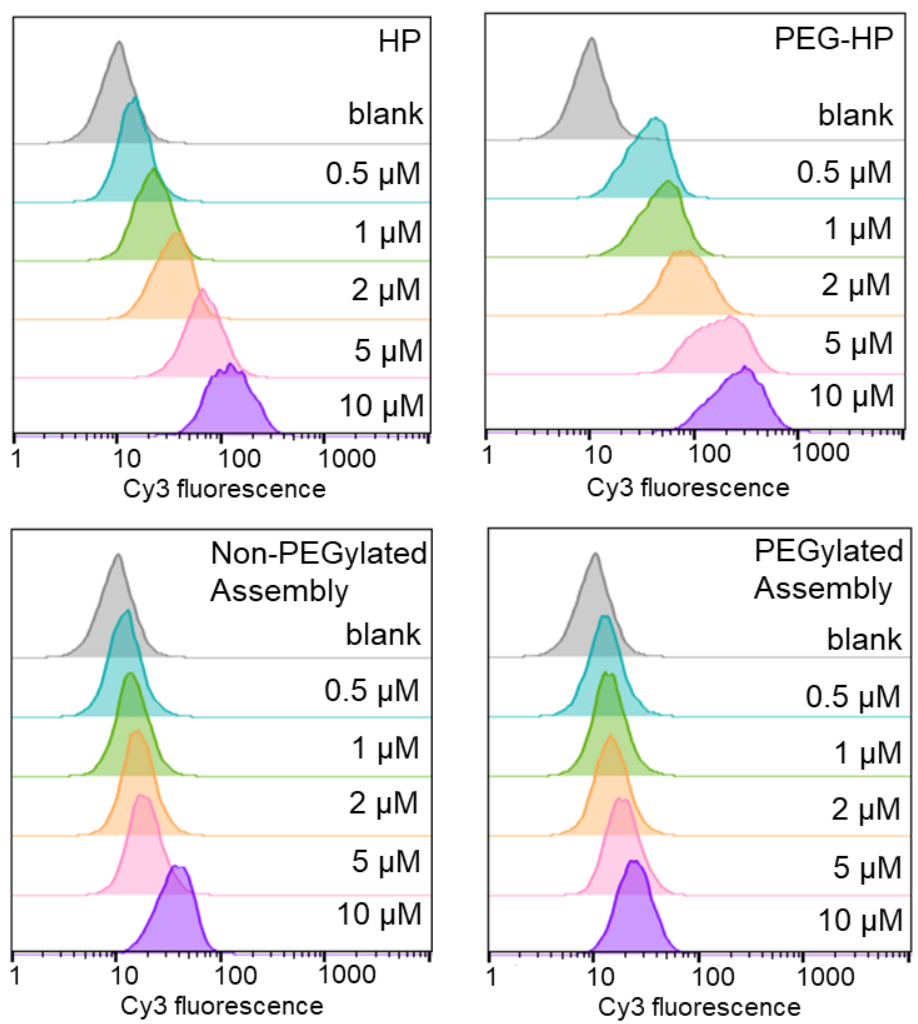

Figure S10. Flow cytometry measurement of PC9 cells treated with DNA assemblies and their monomers.
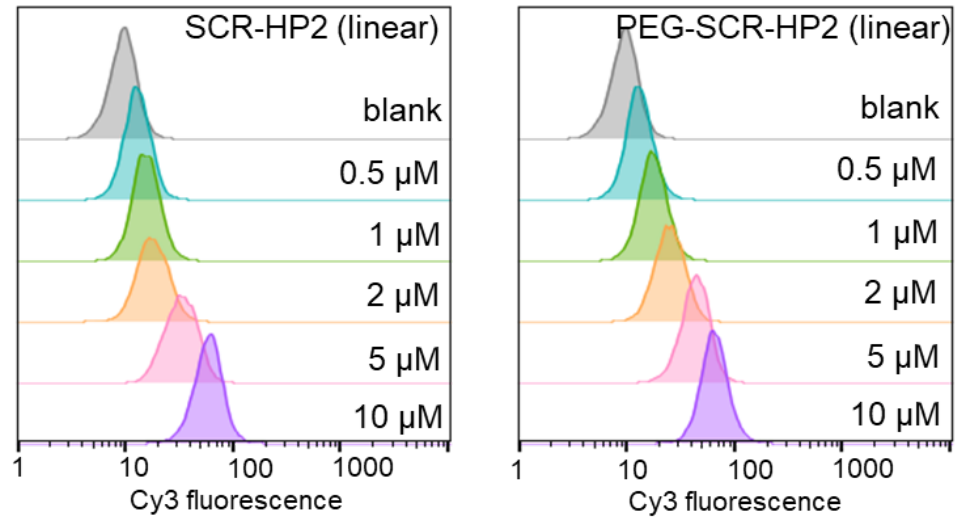

Figure S11. Flow cytometry measurement of NCI-H358 cells treated with scrambled strands and PEGylated scrambled strands. 


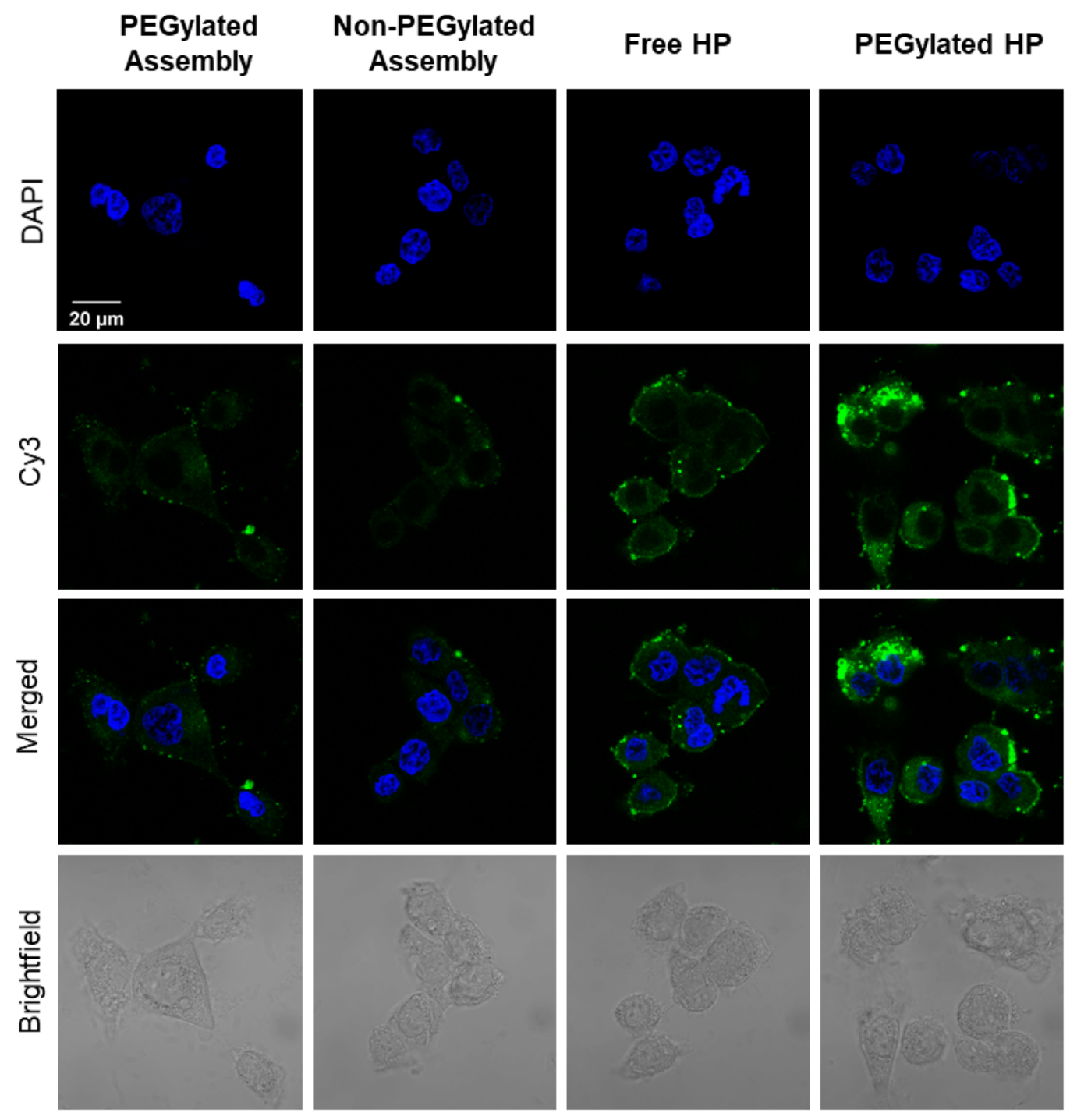

Figure S12. Confocal microscopy images of cells treated with Cy3-labeled DNA assemblies and their precursors in serum-free RPMI medium for $24 \mathrm{~h}$. 
PEGylated HP2

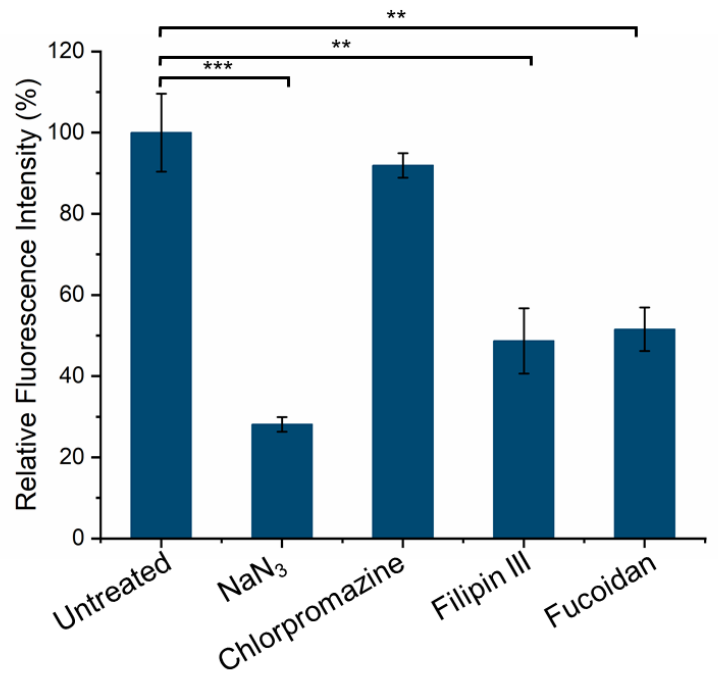

PEGylated Assembly

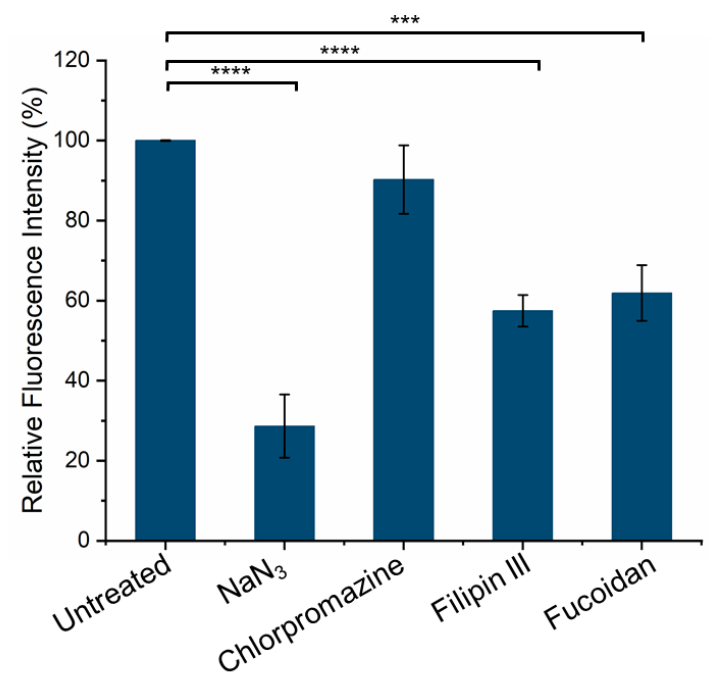

Figure S13. Relative cellular uptake of PEGylated HP2 and PEGylated assembly in NCI-H358 cells pretreated with pharmacological inhibitors. ${ }^{*} P<0.01, * * * P<0.001 * * * * P<0.0001$ (twotailed test).
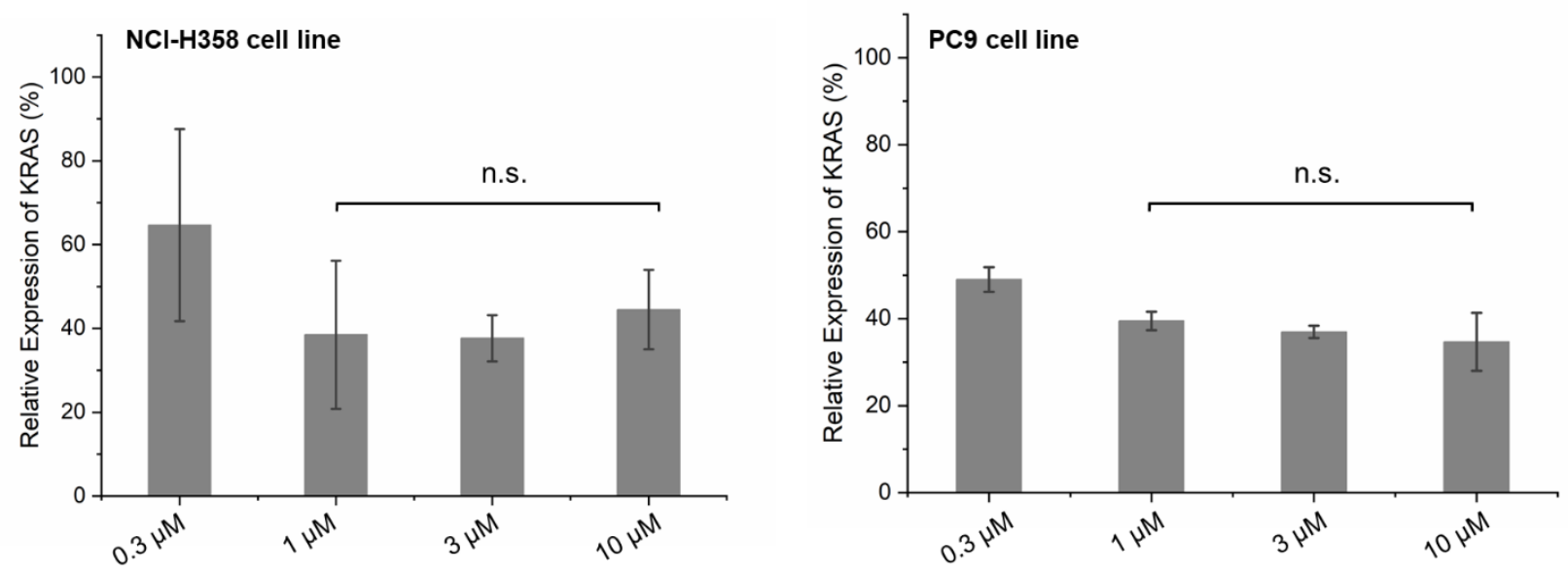

Figure S14. KRAS knockdown (protein level) in NCI-H358 and PC9 cell lines by PEGylated assembly. Level of knockdown no longer shows dosage-response beyond $1 \mu \mathrm{M}$ of antisense strand.

1. Li, Z.; He, X.; Luo, X.; Wang, L.; Ma, N., DNA-Programmed Quantum Dot Polymerization for Ultrasensitive Molecular Imaging of Cancer Cells. Anal Chem 2016, 88 (19), 93559358.

2. Zadeh, J. N.; Steenberg, C. D.; Bois, J. S.; Wolfe, B. R.; Pierce, M. B.; Khan, A. R.; Dirks, R. M.; Pierce, N. A., Nupack: Analysis and Design of Nucleic Acid Systems. J Comput Chem 2011, 32 (1), 170-173. 